\title{
Ophthalmology and Therapy: Looking Back at 2018 and Forward to 2019
}

Tariq Aslam

Received: January 11, 2019 / Published online: January 25, 2019

(C) The Author(s) 2019

Keywords: Artificial intelligence; Cataracts; Diabetic retinopathy; Dry eye; Genetics; Glaucoma; Macular degeneration; OCT-A; Ophthalmology

Dear Readers,

As we reflect on Ophthalmology and Ther$a p y^{\prime} s$ successes in 2018 and anticipate another rewarding year for the journal in 2019, it is important to acknowledge the tremendous support from our authors, readers, reviewers, and Editorial and Advisory Boards. The journal would not operate without the culmination of these groups and so for this we are truly grateful.

Thank you to all of our Editorial Board members who are responsible for assisting the in-house editorial, contributing their own research, suggesting review topics and generally supporting the journal in its development. Thank you also to our Advisory Board who are primarily responsible for providing peer review comments. This support allows us to maintain our rapid publication timelines and publish

Enhanced digital features To view enhanced digital features for this article, go to https://doi.org/10.6084/ m9.figshare.7577828.

T. Aslam $(\varangle)$

Manchester Royal Eye Hospital, Manchester, UK e-mail: Tariq.Aslam@mft.nhs.uk research in the timely manner it deserves. Of course, we must thank all of our reviewers who we reward with a free publication (pending peer review) for every three reviews completed per calendar year. A complete list of our current Editorial and Advisory Board members can be found here https://www.springer.com/ springer+healthcare/journal/40123?detailsPage $=$ editorialBoard.

In 2018, the readership of the journal was over 135,000 . Some of the most highly read articles within 2018 included:

- Continuous Transitional Focus (CTF): A New Concept in Ophthalmic Surgery. Mesa, R.R. \& Monteiro, T. Ophthalmol Ther (2018) 7: 223 https://link.springer.com/article/10. 1007/s40123-018-0134-x. A narrative review assessing the latest advancements in continuous transitional focus lenses with over 2100 downloads.

- A Review of Laser-Assisted Versus Traditional Phacoemulsification Cataract Surgery. Dick, H. \& Schultz, T. Ophthalmol Ther (2017) 6: 7 https://link.springer.com/article/10.1007/ s40123-017-0080-z. A narrative review comparing laser-assisted and traditional phacoemulsification cataract surgery which has been downloaded over 4900 times and cited three times.

- "Doctor, I have a Sulfa Allergy": Clarifying the Myths of Cross-Reactivity. Shah, T.J., Moshirfar, M. \& Hoopes, P.C. Ophthalmol 
Ther (2018) 7: 211 https://link.springer.com/ article/10.1007\%2Fs40123-018-0136-8. A commentary article from our Advisory Board member Majid Moshirfar whose article provides practical guidance for eye-care specialists and has been downloaded over 1700 times.

- Treatment of Dry Eye Disease with Autologous Platelet-Rich Plasma: A Prospective, Interventional, Non-Randomized Study. Alio, J.L., Rodriguez, A.E., Ferreira-Oliveira, R. et al. Ophthalmol Ther (2017) 6: 285 https://link.springer.com/article/10.1007\% 2Fs40123-017-0100-z. Our Editorial Board member Jorge Alio published an original research article investigating autologous platelet-rich plasma as a treatment for dry eye and has been downloaded 2000 times with 11 citations.

- Three-Year Outcomes of Aflibercept Treatment for Neovascular Age-Related Macular Degeneration: Evidence from a Clinical Setting. Eleftheriadou, M., Gemenetzi, M., Lukic, M. et al. Ophthalmol Ther (2018) 7: 361 https://link.springer.com/article/10. 1007\%2Fs40123-018-0139-5. Our Editorial Board member Praveen Patel published an original research article looking at the realworld implications of aflibercept treatment and has been downloaded 835 times and cited once.

- "Minimally Invasive Glaucoma Surgery (MIGS) Is a Poor Substitute for Trabeculectomy"-The Great Debate. Bloom, P. \& Au, L. Ophthalmol Ther (2018) 7: 203 https:// link.springer.com/article/10.1007\%2Fs4012 3-018-0135-9. The first debate style commentary article published in Ophthalmology and Therapy based on a debate at "The Royal College of Ophthalmologists Annual Congress 2018". This has been downloaded over 600 times.

We are really pleased to be publishing more enhanced digital features such as videos and slide sets. These peer-reviewed features accompany the main article and are designed to increase the educational value of the content.

We have also begun publishing optional plain language summaries alongside the standard scientific abstract to aid understanding and increase dissemination of research to nonexperts, including non-specialists, patients, caregivers and others. An example from Biswas, $S$ et al.'s cystinosis review published earlier this year can be found here https://link.springer. com/article/10.1007/s40123-018-0146-6.

Looking back, 2018 has been a year of wideranging and exciting medical and technological developments that are too numerous to mention. My key aspirations for 2019 would simply be towards the translation of some of these exciting findings to my patients in routine clinical practice.

Aside from the many possible regimens, new and distinct agents to treat diabetic retinopathy and choroidal neovascularisation would be very welcome, such as those causing combined blockade of angiopoetin-2 and vascular endothelial growth factor-A (VEGF-A) - part of ongoing trials looking to improve upon the revolutionary advances seen in wet age-related macular degeneration (AMD) and diabetic treatment of the last decade. Further advances in these conditions may be through improving the method of delivery or reducing demands for frequent invasive treatments, with trials for topical anti-VEGF agents (PanOptica) as an example of potentially paradigm-shifting treatments. Similarly, I look forward to progress with randomised controlled trials providing clear evidence-based guidance on using modern laser technologies such as subthreshold laser on macular fluid.

Perhaps even more desperately needed are treatments for dry macular degeneration including geographic atrophy. We must hope that trials that have demonstrated benefits in early-stage studies (e.g., FILLY-using APL-2) will continue to progress successfully through phase 3 studies.

Despite decades of research investment in genetics, few treatments demonstrated to be effective, visually significant and clinically valid have become available. Dozens of ocular gene therapy trials are in progress, with many centred on monogenetic inherited retinal disorders. However, recent approval of Luxturna for RPE65 disorders has potentially answered the call for ocular gene therapy to move from bench to bedside and the treatments will be watched 
with great interest to confirm how patients respond and to build on evidence for visual gains with robust and reliable measures. Choroideremia, X-linked retinitis pigmentosa (XLRP), X-linked retinoschisis and achromatopsia also have trials in progress along with plans for studies in acquired disorders such as AMD.

Recent years have seen an explosion in capabilities for improving resolution and modalities of imaging. Optical coherence tomography angiography (OCT-A), multicolour scanning laser ophthalmoscopy, adaptive optics, blue, green and near-infrared as well as wide field autofluorescence, swept source/enhanced depth imaging of the choroid are all technologies that have demonstrated ever-improving and incredible images. However, clinical utility lags somewhat behind the evident technical achievements, with more work required on how each of these technologies should ideally be used. Interpretation of these ever-increasing types and detail of scans provides opportunity for improved management through greater understanding of multimodal imaging. Many articles in 2018 have demonstrated the awesome power of machine-learning algorithms as part of artificial intelligence (AI) systems to analyse images. The AI focus now needs to be shifted toward practical benefits and how they should be realised, in particular how exactly AI systems will act to plug existing strains and gaps in delivery of medical care, alongside existing infrastructure and staff to improve patient outcomes.

As well as ophthalmologists exploring precision analysis of tiny areas of ophthalmic anatomy, this last year has seen developing interest in addressing overall patient well-being; strands of research into prevalence of depression and anxiety in macular degeneration have expanded into wider appreciation of a need to see patients holistically, appreciating deeper needs beyond the millimetres of tissue we normally inspect.

In summary, the field of medical retinal disease has been transformed in recent years by development and very rapid spread of management strategies based around injection of intravitreal anti-VEGF agents. In this time, imaging, processing and analysis have been transformed and progressed at a remarkable pace with current widespread accessibilities of technologies such as OCT-A and AI. Similarly, development and investigation of many new treatment strategies and modalities, including gene therapy, biologics and optogenetics, have provided optimism for future patient care. However, relative to the vast amounts of research and investigation, there are a few new options for treatment of the common medical retina conditions. My hope for this coming year is the realisation of proven new treatments or strategies, ready for use in clinical practice, especially for those conditions untouched by the original spark of anti-VEGF that a decade ago set our specialty alight.

We invite our readers to consider submitting their work to Ophthalmology and Therapy. As discussed, there are a number of upcoming, exciting developments in ophthalmology, which we look forward to publishing in 2019.

Tariq Aslam, Editor-in-Chief Europe.

\section{ACKNOWLEDGEMENTS}

Peer Review. Please note, contrary to the journal's standard single-blind peer review process, as an editorial written by the Editor-inChief of the journal this article was not peerreviewed.

Funding. No funding or sponsorship was received for this study or publication of this article.

Authorship. All named authors meet the International Committee of Medical Journal Editors (ICMJE) criteria for authorship for this article, take responsibility for the integrity of the work as a whole, and have given their approval for this version to be published.

Disclosures. Tariq Aslam discloses the following: consultant and advisor/research grants from Novartis, Bayer, Bausch and Lomb, Oraya and Thea. 
Compliance with Ethics Guidelines. This article is based on previously conducted studies and does not contain any studies with human participants or animals performed by any of the authors.

Open Access. This article is distributed under the terms of the Creative Commons Attribution-NonCommercial 4.0 International
License (http://creativecommons.org/licenses/ by-nc/4.0/), which permits any noncommercial use, distribution, and reproduction in any medium, provided you give appropriate credit to the original author(s) and the source, provide a link to the Creative Commons license, and indicate if changes were made. 